\title{
TEMPERATURA, LUZ E SUBSTRATO PARA GERMINAÇÃO DE SEMENTES DE PAU-BRASIL (Caesalpinia echinata Lam., Leguminosae - Caesalpinioideae) ${ }^{1}$
}

\author{
Juliana Iura de Oliveira Mello² e Claudio José Barbedo ${ }^{3}$
}

\begin{abstract}
RESUMO - Programas de preservação de Caesalpinia echinata, espécie considerada em risco de extinção, incluem a conservação $e x$ situ, que poderia ser ainda mais intensificada pelo armazenamento, no longo prazo, de suas sementes. Embora já se tenha desenvolvido tecnologia suficiente para preservar a germinabilidade dessas sementes por até dois anos, ainda são insuficientes as informações acerca das condições adequadas para a germinação, mormente as referentes a temperatura, luz e substrato. Este trabalho visou avaliar os efeitos de temperaturas constantes de $10 \mathrm{a} 45^{\circ} \mathrm{C}$ em presença ou ausência de luz e o tipo (papel, areia e vermiculita) e umidade do substrato sobre a germinação das sementes de pau-brasil. Concluiu-se que a semeadura deve ser realizada em rolo de papel, umedecido na relação 1:2,5 a 1:3,0 (substrato:água, em massa), e na temperatura de $25^{\circ} \mathrm{C}$, sem necessidade de luz.
\end{abstract}

Palavras-chave: Análise de sementes, teste de germinação e umidade.

\section{TEMPERATURE, LIGHT AND SUBSTRATE FOR GERMINATION OF SEEDS OF BRAZILWOOD (Caesalpinia echinata Lam., Leguminosae - Caesalpinioideae)}

\begin{abstract}
Preservation of the Brazilian endangered tree Caesalpinia echinata Lam. include the ex situ conservation that could be enhanced by the long term storage of its seeds. In despite of having enough technology to preserve brazilwood seed viability for at least two years, there is scarce information on the optimal conditions for germination, mainly concerning temperature, light and substrate. This research aimed to study the effects of the constant temperatures $\left(10\right.$ to $\left.45^{\circ} \mathrm{C}\right)$, the presence or absence of light and the moisture content of three substrates (paper, sand and vermiculite) on the germination of C. echinata seeds. The results suggested that these seeds should be sowed on paper roll moistened at the ratio 1:2.5 or 1:3.0 (substrate: water, w/w) at $25^{\circ} \mathrm{C}$, no need for light.
\end{abstract}

Keywords: Seed analysis, germination test and moisture content.

\section{INTRODUÇÃO}

Caesalpinia echinata Lam. (Leguminosae Caesalpinioideae), o pau-brasil, ou ibirapitanga, foi explorado desde o início da colonização brasileira quando, como primeira riqueza econômica do país, constituía matériaprima para a produção de corante de tonalidade avermelhada (brasileína). Apresenta valor econômico até os dias atuais, pois sua madeira, utilizada na confecção de arcos de violino, é considerada de qualidade única (ROCHA, 2004). Embora outras madeiras estejam sendo pesquisadas e empregadas no comércio nacional para a produção de arcos, a madeira de pau-brasil, mundialmente utilizada nessa confecção, apresenta características únicas de ressonância, densidade, durabilidade e beleza (ANGYALOSSY et al., 2005).

\footnotetext{
${ }^{1}$ Recebido em 29.04.2006 e aceito para publicação em 15.11.2006

${ }^{2}$ Programa de Pós-Graduação em Biodiversidade Vegetal e Meio Ambiente do Instituto de Botânica. Av. Miguel Stéfano, 3687 , 04301-012 São Paulo-SP.

${ }^{3}$ Seção de Sementes e Melhoramento Vegetal do Instituto de Botânica e bolsista CNPq. E-mail: <claudio.barbedo@ @esquisador.cnpq.br>.
} 
A despeito de sua atual raridade natural, há diversas iniciativas, públicas e privadas, para a preservação ex situ da espécie, principalmente no Estado de São Paulo (ROCHA, 2004). Para que a preservação e a utilização da espécie sejam eficientes, a produção e armazenamento de suas sementes como forma de conservação ex situ assume papel fundamental e, nesse caso, há necessidade de monitoramento da capacidade germinativa dessas sementes.

O teste de germinação, que avalia essa germinabilidade, deve ser realizado sob condições de temperatura e substrato ideais para cada espécie (GOMES eBRUNO, 1992). Contudo, não existe uma temperatura ótima e uniforme na qual se enquadrem todas as espécies (BORGES e RENA, 1993). Sementes de plantas de regiões temperadas geralmente germinam entre zero $35^{\circ} \mathrm{C}$, enquanto as de regiões tropicais germinam entre $10 \mathrm{e} 45^{\circ} \mathrm{C}$ (MWALE et al., 1994). Sementes de plantas nativas do Brasil podem germinar em ampla faixa térmica, dependendo do bioma e da região e parecem apresentar uma relação positiva entre a temperatura ótima e o regime térmico da região de sua ocorrência natural (BORGHETTI, 2005).

A temperatura exerce grande influência sobre a velocidade e porcentagem final da germinação. Intracelularmente, a temperatura influencia as reações bioquímicas que determinam o processo germinativo, pois há uma seqüência programada de reações químicas cujos sistemas enzimáticos apresentam exigências térmicas próprias (MARCOS FILHO, 2005). As baixas temperaturas podem reduzir as taxas metabólicas até que as vias essenciais ao início da germinação não possam mais operar (HENDRICKS e TAYLORSON, 1976), enquanto as altas acarretam diminuição no suprimento de aminoácidos livres, da síntese de RNA e de proteínas, assim como decréscimo na velocidade das reações metabólicas (RILEY, 1981).

Além da temperatura, o substrato utilizado nos testes de germinação interfere no resultado final, atuando diretamente na aeração, estrutura e capacidade de retenção de água, além do grau de infecção de patógenos (POPINIGIS, 1985). Nesses testes, o substrato deve permanecer uniformemente úmido, a fim de suprir as sementes da quantidade de água necessária para sua germinação e desenvolvimento. O excesso de água pode acarretar aceleração da deterioração, com condições favoráveis ao desenvolvimento de microrganismos, enquanto a falta de água pode interromper processos metabólicos importantes. Contudo, a adição de água no decorrer do teste deve ser evitada, para não alterar as condições de germinação, tornando essencial o controle da quantidade inicial a ser adicionada ao substrato. Essa quantidade depende da natureza e dimensão do substrato e, principalmente, das exigências de cada espécie (FIGLIOLIA et al., 1993; MARCOS FILHO, 2005).

A luz nem sempre é fator limitante para a germinação de sementes (FIGLIOLIA et al., 1993), mas sua presença pode contribuir para atenuar problemas causados pelo baixo potencial de água no solo e os efeitos de temperaturas superiores à ótima (MARCOS FILHO, 2005). Por meio das diferentes formas do fitocromo (phy), a semente pode perceber a luz de fluência muito baixa e ter sua germinação inibida pela luz branca de fluência alta (fitocromo A - phy A) ou pela ação do fitocromo B (phyB), perceber a razão vermelho:vermelho extremo e ter a germinação promovida (TAKAKI, 2005).

Este trabalho visou avaliar a influência da temperatura, do tipo e do grau de umedecimento do substrato e da presença ou ausência de luz na germinação das sementes de pau-brasil.

\section{MATERIAL E MÉTODOS}

Sementes maduras (BORGES et al., 2005b) de Caesalpinia echinata Lam., foram obtidas de bosque implantado na Reserva Ecológica e Estação Experimental de Moji-Guaçu, Mogi-Guaçu, SP (22 ${ }^{\circ} 15-16^{\prime}$ S, $47^{\circ} 8$ $\left.12^{\prime} \mathrm{W}\right)$ e armazenadas por 60 dias em câmara fria (7 ${ }^{\circ} \mathrm{C}$, conforme recomendação de Barbedo, 2005), apresentando $8,2 \%$ de água ao final desse período. Os experimentos de temperatura, luz e umidade de substratos foram realizados no Laboratório de Sementes do Instituto de Botânica, em São Paulo, SP, em germinadores tipo Marconi MA400, com circulação interna de água, que mantém elevada umidade relativa do ar (100\%), com a iluminação por quatro lâmpadas fluorescentes Philips de $15 \mathrm{~W}$ verticais, fornecendo fluxo de energia de $437 \mathrm{iW} . \mathrm{cm}^{-2}$.

Todos os experimentos foram instalados com quatro repetições de 16 sementes, avaliados a cada três dias (BORGES et al., 2005b). Foram calculados o índice de velocidade de germinação (IVG, segundo fórmula de MAGUIRE, 1962), o tempo médio de germinação e a variância do tempo médio de germinação (LABOURIAU, 1983) e as porcentagens de germinação e de plântulas normais desenvolvidas (BORGES et al., 2005b). Também, foram confeccionados os gráficos de freqüência relativa de germinação (BORGHETTI e FERREIRA, 2004). 


\subsection{Temperatura $\mathrm{x}$ luz}

Os efeitos da temperatura e da luz sobre a germinação de sementes de C. echinata foram avaliados por meio da utilização de oito diferentes regimes térmicos de 10 a $45^{\circ} \mathrm{C}$ constantes, num intervalo de $5^{\circ} \mathrm{C}$ e variação máxima de $1{ }^{\circ} \mathrm{C}$, associados a dois regimes luminosos (luz branca ou escuro total, contínuos). As sementes foram semeadas em caixas de germinação tipo gerbox $(11 \times 11 \times 3 \mathrm{~cm})$ sobre papel previamente umedecido com água destilada até a saturação e sem excesso. No tratamento de escuro total, o gerbox utilizado foi o preto, que não permite a passagem de luz, enquanto o tratamento de luz branca foi instalado em gerbox transparente. As avaliações do tratamento de escuro total foram realizadas sob luz verde de segurança. A duração dos testes foi de 21 dias.

\subsection{Substrato $\mathrm{x}$ disponibilidade hídrica}

O efeito da umidade do substrato foi avaliado através da utilização de diferentes quantidades de água para umedecimento de diferentes substratos. Foram testados como substratos a areia, a vermiculita (substratos granulares) e o papel, este avaliado em três tipos de semeadura: sobre papel (SP), entre papel (EP) e rolo de papel (RP), conforme descrito pelas Regras para Análise de Sementes (BRASIL, 1992). Nos tratamentos de substratos granulares, bem como SP e EP, foram utilizadas caixas gerbox transparentes, descritas anteriormente, preenchidas com areia e vermiculita em 3/4 de seu volume total ou, no caso dos substratos de papel, com duas folhas para a base (SP) e uma para cobertura (EP). Nos tratamentos RP, utilizaram-se folhas de papel para germinação, tipo Germitest, cujas dimensões são de 30 × $37 \mathrm{~cm}$.

Previamente ao umedecimento, calculou-se a quantidade de água necessária para o saturamento de cada material, umedecendo-se os substratos com volume conhecido, coletando-se e registrando-se a quantidade de água após seu escoamento dos substratos. A partir desses valores, adotou-se uma relação de substrato:água, em massa, para papel (1:2,5 para EP e SP e 1:3,0 para RP) e em volume $(1: 0,30)$ para os substratos granulares, correspondendo a $250 \mathrm{mg}$ de água por $100 \mathrm{~g}$ de papel (EP e SP), $300 \mathrm{mg}$ água por $100 \mathrm{~g}$ de papel (RP) e 300 $\mathrm{mL}$ de água por $\mathrm{kg}$ de substrato granular.

Além do nível de saturação, foram adotados três níveis de umedecimento, um acima e dois abaixo do nível de saturação. Dessa forma, os tratamentos de umedecimento foram para papel em gerbox, 1:2,5 (papel saturado, mas sem excesso de água), 1:3,0 (papel com pequeno excesso de água, com $300 \mathrm{mg}$ água/100 g de papel), 1:2,0 e 1:1,5 (respectivamente, 200 e $150 \mathrm{mg}$ água/100 g papel); para rolo de papel, 1:3,0 (papel saturado, mas sem excesso de água), 1:3,5 (papel com pequeno excesso de água, com $350 \mathrm{mg}$ água/100 g de papel), $1: 2,5$ e 1:2,0 (respectivamente, 250 e $200 \mathrm{mg}$ água/ 100 g papel); para os granulares, 1:0,30 (substrato saturado, mas sem excesso de água), 1:0,40 (substrato com um pequeno excesso de água, $400 \mathrm{~mL}$ de água/L de substrato), 1:0,25 e 1:0,20 (respectivamente, 250 e $200 \mathrm{~mL}$ de água/ L de substrato). A montagem dos rolos de papel foi feita tendo-se duas folhas de papel como base de semeadura e uma terceira como cobertura, a dos demais tratamentos foi realizada em gerbox transparente, sob luz constante. Baseados nos resultados no experimento de luz $\mathrm{x}$ temperatura, neste todas as sementes foram colocadas para germinar em temperatura de $25^{\circ} \mathrm{C}$.

\subsection{Delineamento experimental e análise estatística}

O delineamento experimental foi inteiramente casualizado. Os resultados foram submetidos à análise de variância (teste $\mathrm{F}$ a $5 \%$ de probabilidade), sendo ajustadas regressões polinomiais (GOMES, 1982). No experimento temperatura $\mathrm{x}$ luz, foi utilizado esquema fatorial 2 × 8 (regime de luz x temperatura) e, no substrato $\mathrm{x}$ disponibilidade hídrica, 2 x 4 (tipo de substrato $\mathrm{x}$ nível de hidratação), para substratos granulares e também 2 x 4 (tipo de substrato x nível de hidratação) para papel em gerbox. O experimento em rolo de papel foi analisado como fator único.

\section{RESULTADOS E DISCUSSÃO}

\subsection{Temperatura $x$ luz}

A germinação, o desenvolvimento de plântulas normais, o índice de velocidade de germinação (Figura 1) e a variância do tempo médio (Figura 2B) não apresentaram efeito significativo sobre a interação luz $\mathrm{x}$ temperatura ou efeito isolado nos tratamentos de luz ou escuro contínuos. O tempo médio de germinação (Figura 2A), por sua vez, embora tendo apresentado interação significativa entre efeitos de temperaturas e de luz, tanto para germinação sob luz contínua quanto sob escuro contínuo, apresentou tendência de diminuição (quadrática para luz e linear para escuro) desde os 15

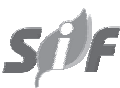

R. Árvore, Viçosa-MG, v.31, n.4, p.645-655, 2007 
até os $35^{\circ} \mathrm{C}$. Pode-se assumir, portanto, que sementes de pau-brasil mostraram-se indiferentes à luz para germinar, o que poderia explicar as respostas semelhantes observadas para germinação de sementes de pau-brasil em diferentes níveis de sombreamento (AGUIAR et al., 2005).
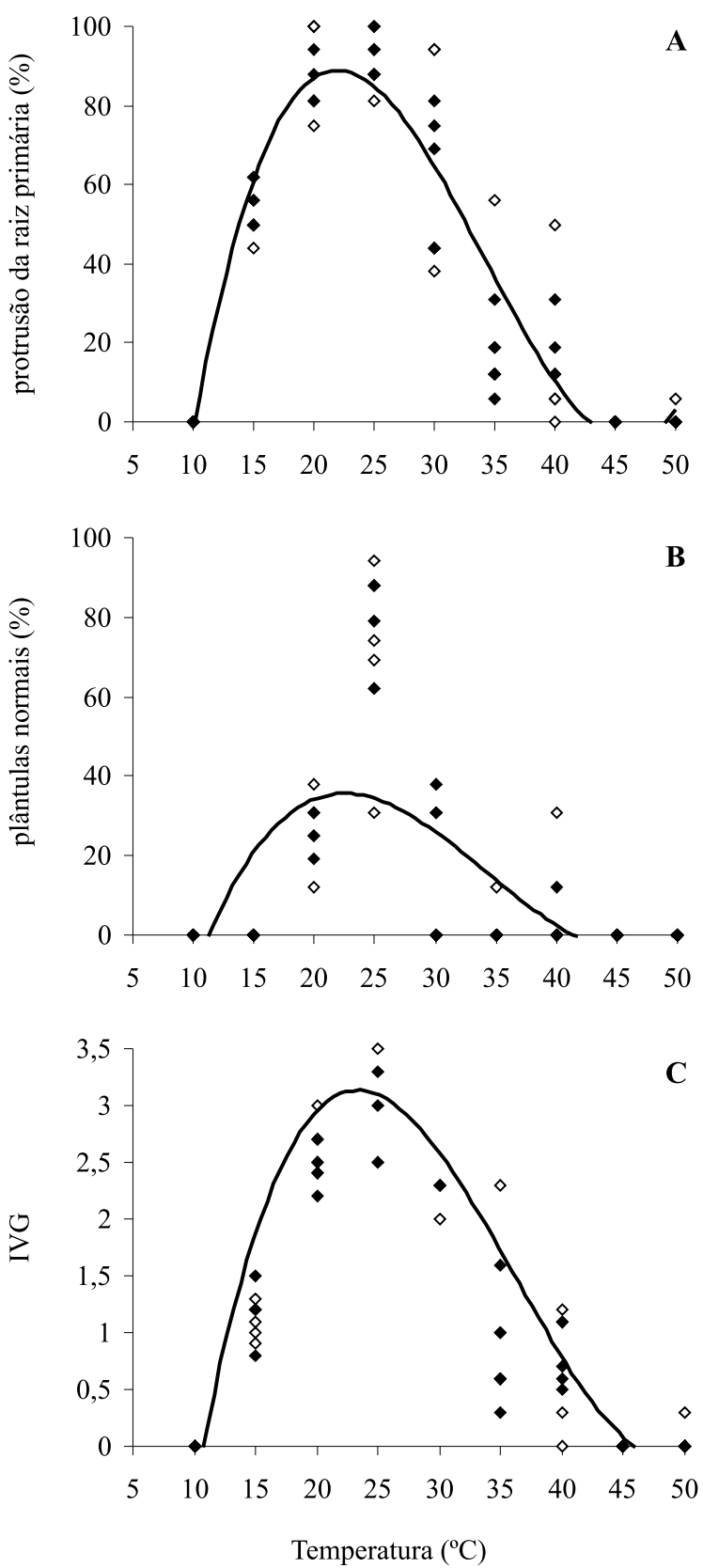

Figura 1 - Germinação (A: protrusão da raiz primária, $Y=-282,74+40,23 X-1,35 X^{2}+0,013 X^{3}, r^{2}=0,88$; B: desenvolvimento de plântulas normais, $\left.\mathrm{Y}=-143,26+19,07 \mathrm{X}-0,63 \mathrm{X}^{2}+0,006 \mathrm{X}^{3}, \mathrm{r}^{2}=0,47\right)$ e índice de velocidade de germinação $(\mathrm{C}$ : $\left.\mathrm{Y}=-9,95+1,33 \mathrm{X}-0,004 \mathrm{X}^{2}+0,0004 \mathrm{X}^{3}, \mathrm{r}^{2}=0,76\right)$ de sementes de Caesalpinia echinata $\mathrm{Lam}$. em diferentes temperaturas. Símbolos abertos: luz contínua; fechados: escuro contínuo.

Figure 1-Germination (A: radicle protrusion; B: normal seedlings) and germination speed (C) of seeds of Caesalpinia echinata Lam. at different temperatures. Open symbols: light; closed symbols: dark.

R. Árvore, Viçosa-MG, v.31, n.4, p.645-655, 2007 

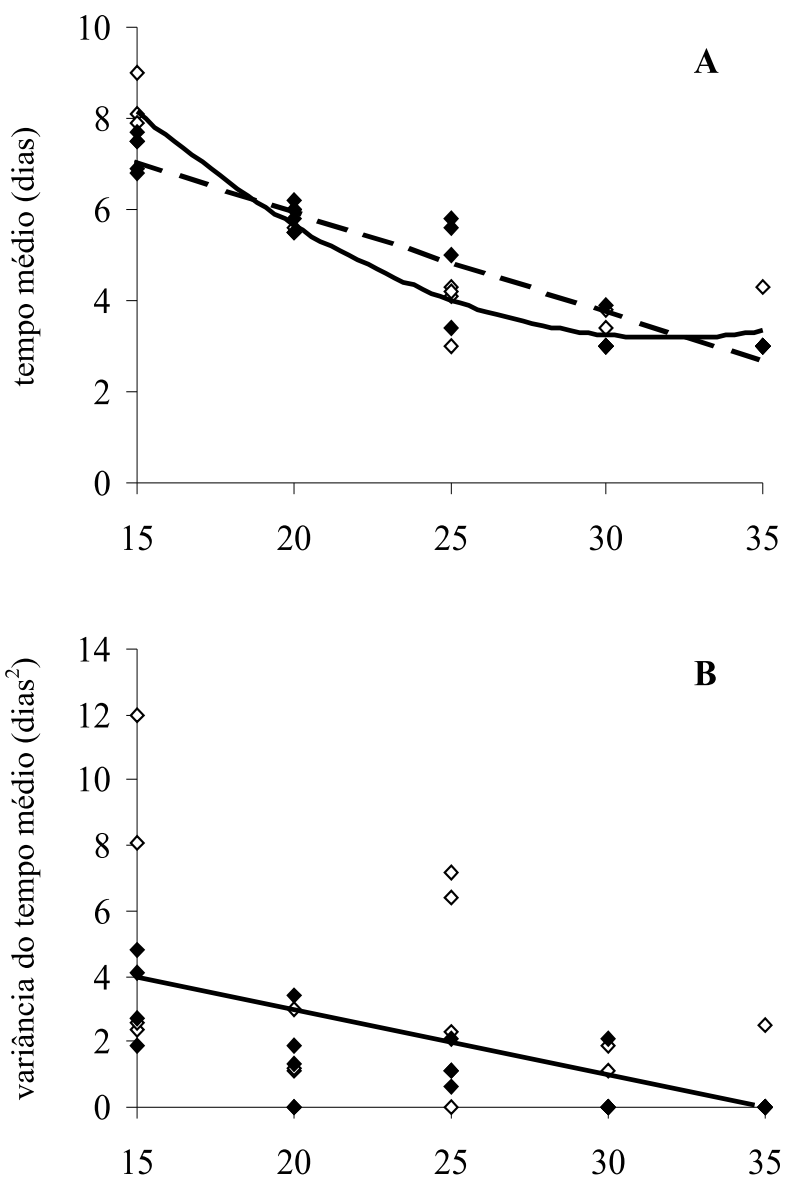

Temperatura $\left({ }^{\circ} \mathrm{C}\right)$

Figura 2 - Tempo médio (A. linha contínua: luz contínua, $\mathrm{Y}=20,82-1,10 \mathrm{X}+0,02 \mathrm{X}^{2}, \mathrm{r}^{2}=0,94$; linha tracejada: escuro contínuo, $\left.Y=10,4-0,22 X, r^{2}=0,88\right)$ e variância do tempo médio ( $\left.\mathrm{B}, \mathrm{Y}=6,91-0,198 \mathrm{X}, \mathrm{r}^{2}=0,29\right)$ da germinação de sementes de Caesalpinia echinata Lam. em diferentes temperaturas. Símbolos abertos, luz contínua; fechados: escuro contínuo.

Figure 2-Mean time (A. full line: light; dotted line: dark) and variance of the mean time $(B)$ for germination of seeds of Caesalpinia echinata Lam. at different temperatures. Open symbols: light; closed: dark.

A germinação de sementes de pau-brasil ocorre desde 15 até $40^{\circ} \mathrm{C}$ (Figura 1A), faixa essa apresentada para espécies de regiões tropicais (MWALE et al., 1994). A temperatura ótima para a germinação de sementes de espécies brasileiras de clima mais quente (BORGHETTI, 2005) é semelhante aos resultados obtidos para $C$. echinata, cujos valores foram superiores a

$90 \%$, com temperaturas de 20 a $25^{\circ} \mathrm{C}$. Essas sementes não toleraram temperaturas acima de $25^{\circ} \mathrm{C}$, com redução substancial do poder germinativo e, acima de $40{ }^{\circ} \mathrm{C}$, não houve germinação, o que difere das sementes de muitas espécies brasileiras de clima quente, que germinam em temperaturas de até $45^{\circ} \mathrm{C}$ (BORGHETTI, 2005). No entanto, essas sementes seguiram a tendência da maioria das espécies brasileiras de não germinarem abaixo de $15^{\circ} \mathrm{C}$ (BORGHETTI, 2005). Pelas regressões obtidas, pode-se presumir que 15 e $40^{\circ} \mathrm{C}$ sejam as temperaturas cardeais inferior e superior, respectivamente (LABOURIAU, 1983), para sementes de pau-brasil.

As sementes de C. echinata possuem ampla adaptabilidade térmica para iniciar a germinação, mas o mesmo não ocorre no desenvolvimento inicial de suas plântulas (Figura 1B). Nessa variável, apenas as temperaturas de 20 e $25^{\circ} \mathrm{C}$ mostraram-se adequadas, com valores superiores a $70 \%$ para $25^{\circ} \mathrm{C}$. Como o critério para análise de lotes de sementes (BRASIL, 1992) é o tecnológico, ou seja, a porcentagem de sementes capazes de desenvolver plântulas normais, a temperatura mais adequada para a condução desse teste seria de $25^{\circ} \mathrm{C}$.

A velocidade de germinação, medida pelo índice de velocidade de germinação (IVG), atingiu valor máximo na temperatura de $25^{\circ} \mathrm{C}$ (Figura 1C). Já quando medida pelo tempo médio (Figura 2A), a velocidade de germinação foi superior nas temperaturas de 30 e 35 ${ }^{\circ} \mathrm{C}$, aumentando progressivamente o tempo médio para germinação com a redução da temperatura. É interessante notar que na temperatura de $25^{\circ} \mathrm{C}$ a germinação chega a valores máximos em período relativamente curto, cerca de cinco a seis dias após o início da embebição (Figuras $2 \mathrm{~A}$ e 3 ), sendo esse pico próximo ao observado nas sementes de Caesalpinia peltophoroides (BORGES et al., 2005a; PONTES et al., 2006).

As variâncias do tempo médio (Figura 2B) indicaram relação diretamente proporcional entre a temperatura e o sincronismo de germinação. Quanto mais elevada a temperatura de germinação de sementes de pau-brasil, mais concentrada temporalmente ela foi em torno do número médio de dias para germinar. Portanto, quando analisados os resultados de germinabilidade, capacidade de desenvolvimento de plântulas normais, velocidade e sincronismo de germinação, constatou-se que a temperatura ótima para a germinação de sementes de pau-brasil deve-se encontrar em torno de $25^{\circ} \mathrm{C}$.

R. Árvore, Viçosa-MG, v.31, n.4, p.645-655, 2007 

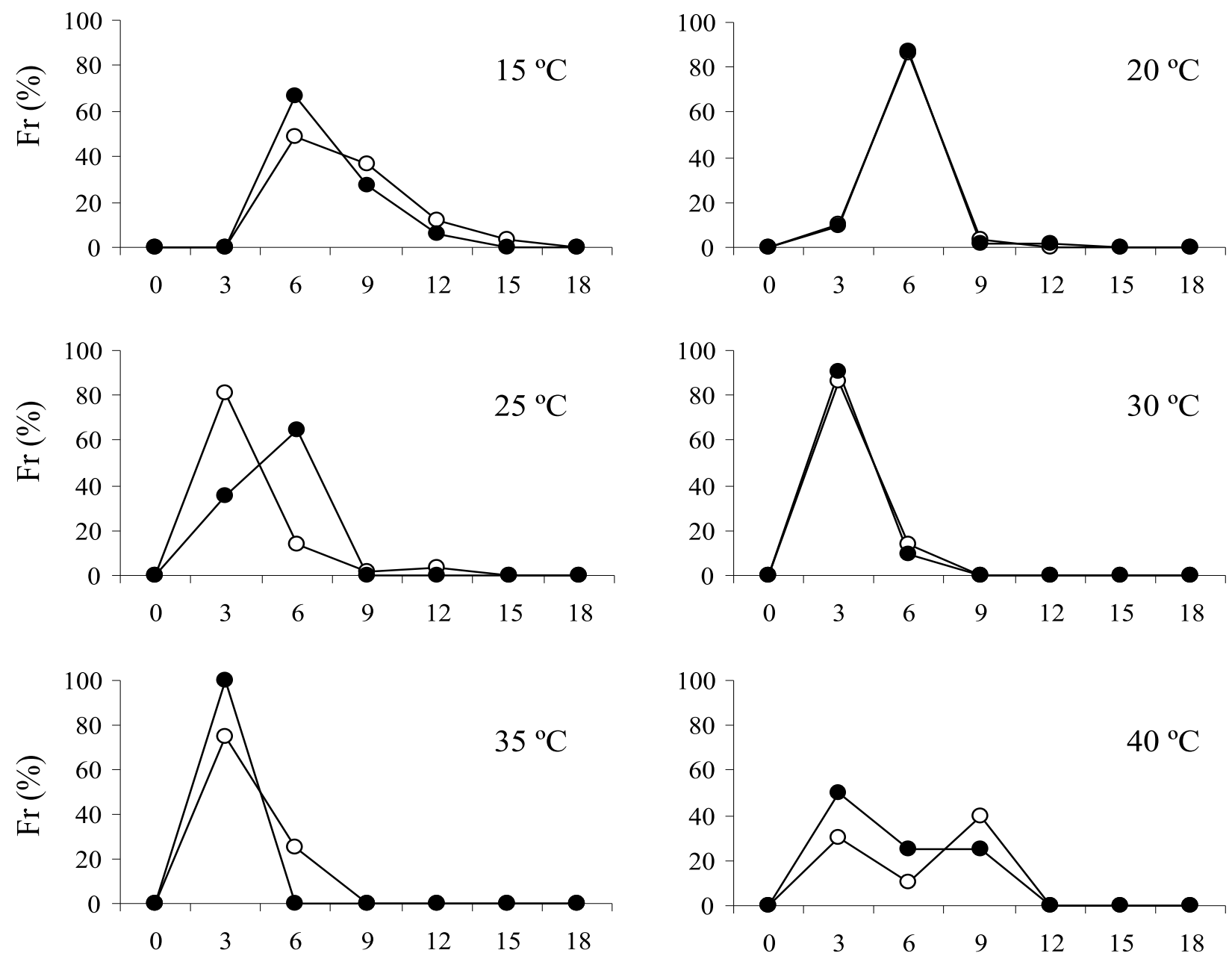

Figura 3 - Distribuição da freqüência relativa (Fr) de germinação de sementes de Caesalpinia echinata Lam. (pau-brasil) em diferentes temperaturas constantes. Círculos vazios, germinação sob luz contínua; círculos cheios, escuro contínuo.

Figure 3 - Relative frequency distribution of germination of Caesalpinia echinata Lam. seeds at different temperatures. Open symbols, germination in continuous light; closed symbols, germination in darkness.

\subsection{Substratos $\mathrm{x}$ disponibilidade hídrica}

Alterações na disponibilidade hídrica, entre os substratos granulares, interferiram mais nos resultados de germinação quando foi utilizada a areia, principalmente em relação ao excesso de água (Figuras 4A, 5A e 6A), com aumento na porcentagem de sementes mortas (dados não apresentados). A incapacidade de germinar em substrato excessivamente úmido e os elevados valores de germinação em substrato relativamente seco podem estar associados à própria distribuição natural da espécie que está restrita às áreas de floresta seca e, originalmente, era abundantemente distribuída na vegetação sazonal semidecidual (GEßLER et al., 2005).

A vermiculita proporcionou boas condições para a germinação das sementes de pau-brasil mesmo com água em excesso. Em se tratando de produção de mudas, com semeadura direta, a vermiculita poderia ser recomendada como substrato adequado tanto para a germinação (Figura 4A) quanto para o desenvolvimento inicial das plântulas (Figura 5A). Contudo, pela sua dificuldade na manipulação e padronização, não é recomendável para testes rotineiros em laboratórios, sendo preferidos os substratos de papel. 


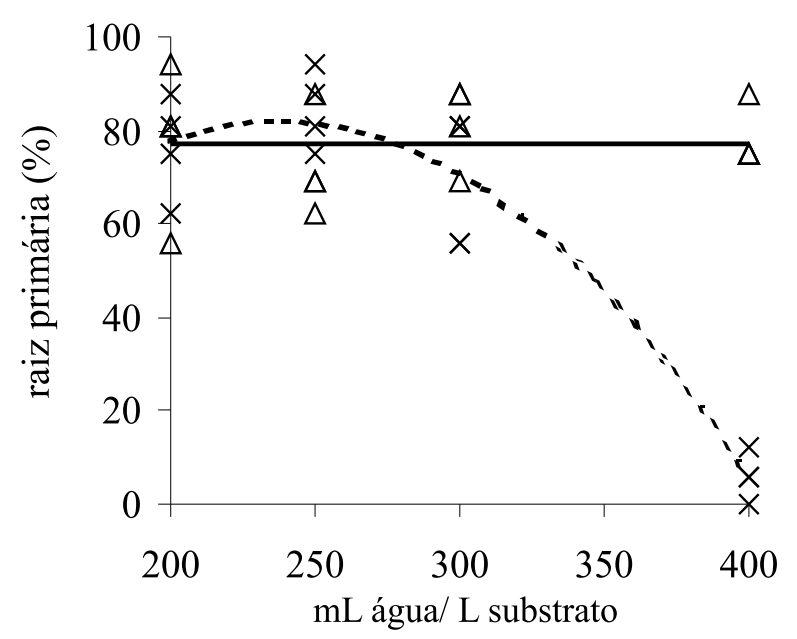

A
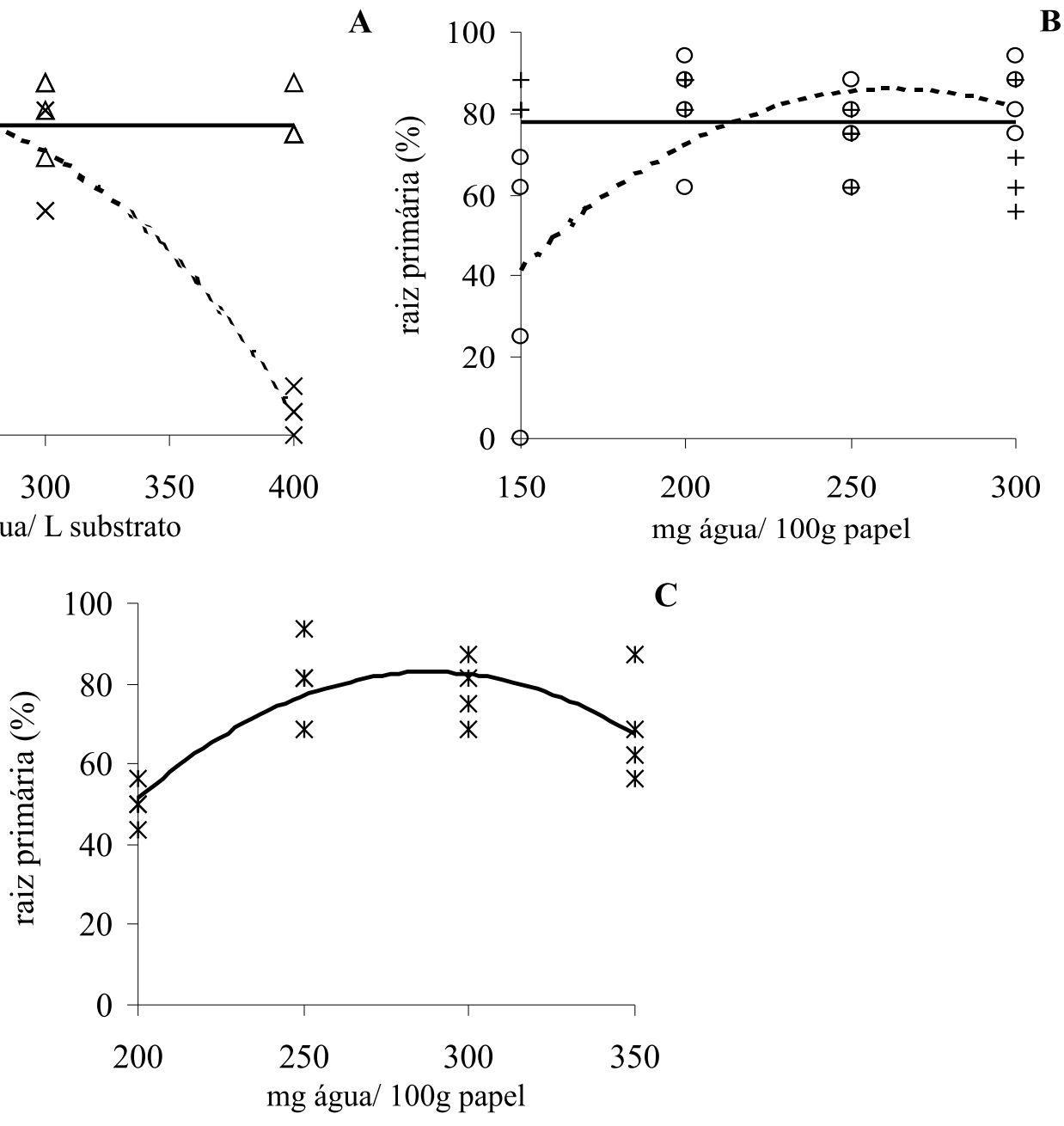

Figura 4 - Germinação de sementes de Caesalpinia echinata Lam. em diferentes substratos e níveis de hidratação. A: substratos granulares ( $\mathrm{x},-$ : areia, $\mathrm{Y}=-83,60+1,39 \mathrm{X}-0,003 \mathrm{X}^{2}, \mathrm{r}^{2}=0,92 ; \Delta$, : vermiculita, $\left.\mathrm{Y}=77,3\right)$; B: substratos em papel, em gerbox (+, - : entre papel, $Y=77,7$; o, - : sobre papel, $\left.Y=-152,03+1,81 X-0,003 X^{2}, r^{2}=0,48\right)$; e C: rolo de papel $\left(\mathrm{Y}=-254,22+2,34 \mathrm{X}-0,004 \mathrm{X}^{2}, \mathrm{r}^{2}=0,63\right)$.

Figure 4-Germination of seeds of Caesalpinia echinata Lam. in different substrates and moisture levels. A: granular substrates ( $x$, , : sand; $\Delta$, -:vermiculite); B: paper in gerbox (+, -: in paper; o, -: on paper); $C$ : paper roll).

Nos substratos de papel (Figura 4BC), a variação na quantidade de água dos diferentes tratamentos evidenciou, da mesma forma que nos substratos granulares, a capacidade das sementes de pau-brasil em germinar quando o substrato não está totalmente saturado. Verificou-se, também, que não houve grande variação nos valores de germinação entre os diferentes substratos EP (entre papel), SP (sobre papel) ou RP (rolo de papel), exceto no nível de menor disponibilidade hídrica (Figura 4BC). Contudo, nota-se evidente superioridade do rolo de papel em proporcionar o melhor substrato para o desenvolvimento inicial das plântulas (Figura 5C). Nesse substrato, as relações em peso para papel e água mais adequadas para a condução do teste de germinação situaramse entre $1: 2,5$ e 1:3,0 (250 a $300 \mathrm{mg}$ de água/100 $\mathrm{g}$ de papel), permitindo as maiores porcentagens de germinação (Figura 4C) e de desenvolvimento de plântulas normais (Figura 5C), bem como germinação mais rápida (Figura 6C).

R. Árvore, Viçosa-MG, v.31, n.4, p.645-655, 2007 


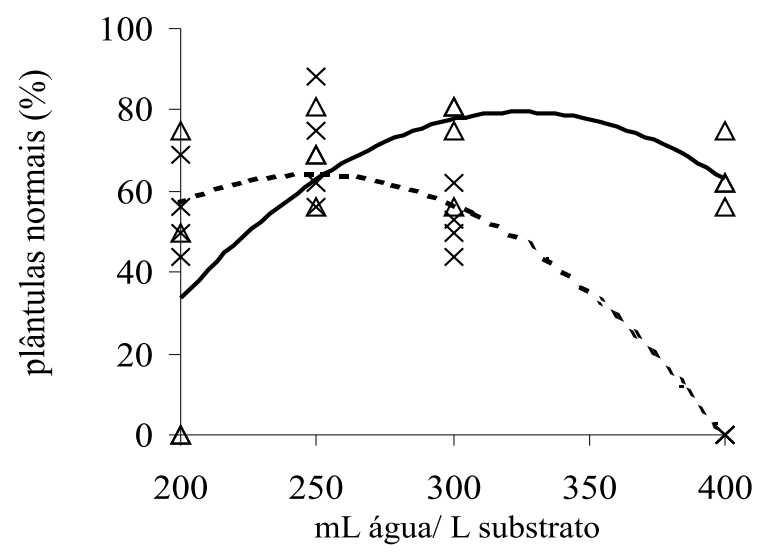

A

B
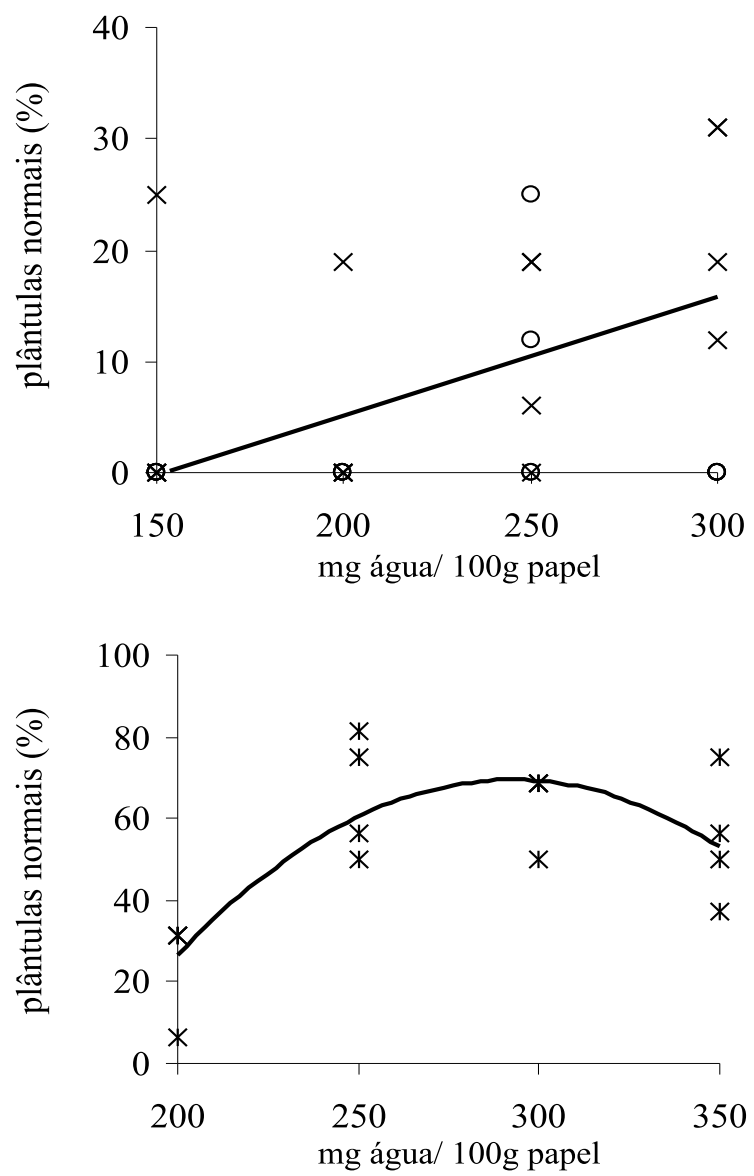

Figura 5 - Desenvolvimento de plântulas normais de sementes de Caesalpinia echinata Lam. em diferentes substratos e níveis de hidratação. A: substratos granulares $\left(\mathrm{x}, \ldots\right.$ : areia, $\mathrm{Y}=-116,13+1,44 \mathrm{X}-0,003 \mathrm{X}^{2}, \mathrm{r}^{2}=0,89 ; \Delta, \ldots$ : vermiculita, $\left.\mathrm{Y}=-231,72+1,91 \mathrm{X}-0,003 \mathrm{X}^{2}, \mathrm{r}^{2}=0,43\right)$; B: substratos em papel, em gerbox (+: entre papel, o: sobre papel, $\mathrm{Y}=-$ $\left.8,28+0,07 \mathrm{X}, \mathrm{r}^{2}=0,13\right)$; e C: rolo de papel $\left(\mathrm{Y}=-339,41+2,78 \mathrm{X}-0,005 \mathrm{X}^{2}, \mathrm{r}^{2}=0,63\right)$.

Figure 5-Normal seedlings from seeds of Caesalpinia echinata Lam. in different substrates and moisture levels. $\Delta:$ granular substrates ( $x, \ldots$ : sand; $\ddot{\mathrm{A}}$, - : vermiculite); B: paper in gerbox (+: in paper, o: on paper); C: paper roll).

R. Árvore, Viçosa-MG, v.31, n.4, p.645-655, 2007 

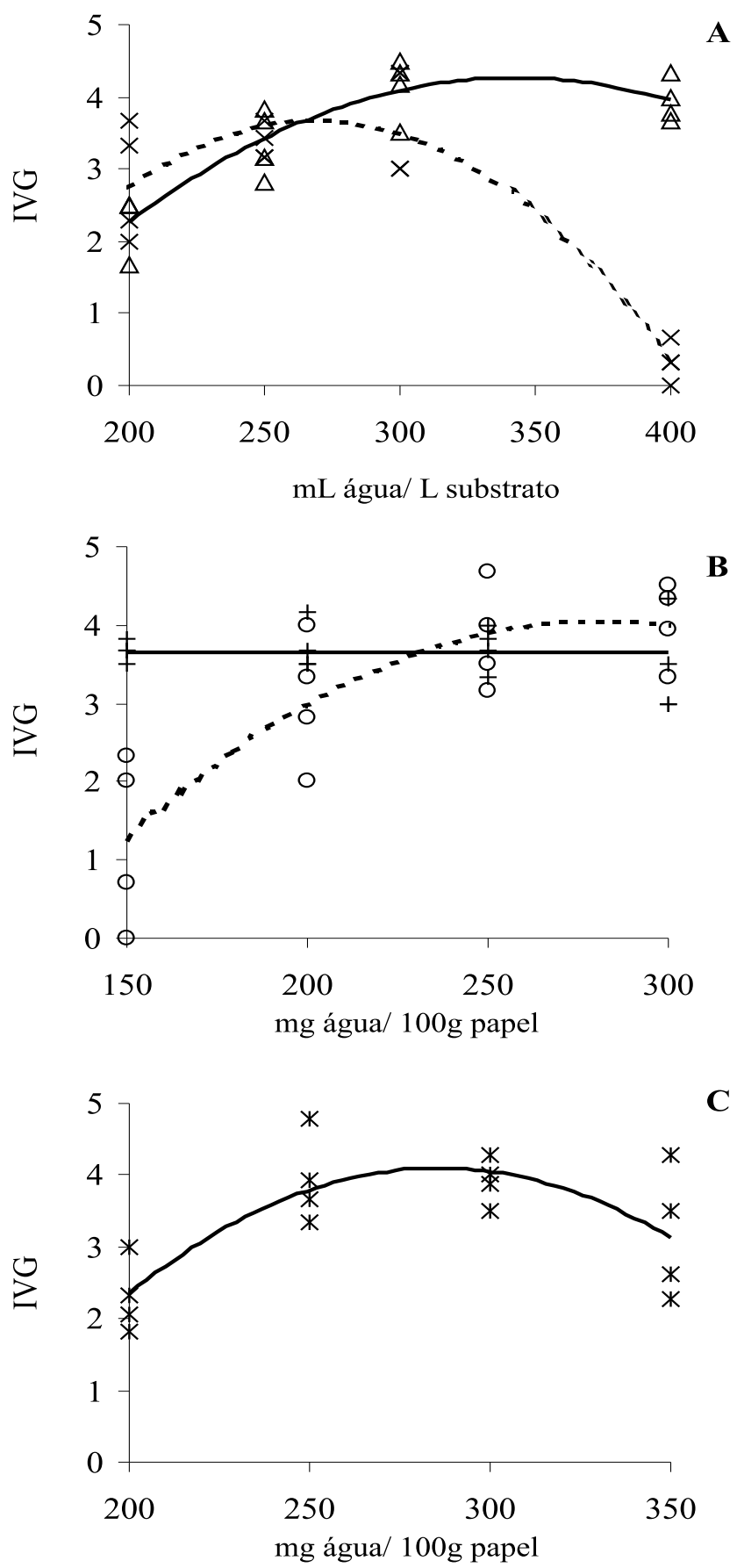

Figura 6 - Índice de velocidade de germinação (IVG) de sementes de Caesalpinia echinata Lam. em diferentes substratos e níveis de hidratação. A: substratos granulares $\left(\mathrm{x},-\right.$ : areia, $\mathrm{Y}=-10,44+0,10 \mathrm{X}-0,0002 \mathrm{X}^{2}, \mathrm{r}^{2}=0,86 ; \Delta,-$ : vermiculita, $\left.\mathrm{Y}=-7,20+0,07 \mathrm{X}-0,0001 \mathrm{X}^{2}, \mathrm{r}^{2}=0,80\right)$; B: substratos em papel, em gerbox $(+,-$ : entre papel, $\mathrm{Y}=3,64 ; \mathrm{o}$, : sobre papel, $\left.\mathrm{Y}=-8,59+0,90 \mathrm{X}-0,0002 \mathrm{X}^{2}, \mathrm{r}^{2}=0,71\right)$; e $\mathrm{C}$ : rolo de papel $\left(\mathrm{Y}=-15,31+0,14 \mathrm{X}-0,002 \mathrm{X}^{2}, \mathrm{r}^{2}=0,59\right)$.

Figure 6-Normal seedlings from seeds of Caesalpinia echinata Lam. In different substrates and moisture levels. A: granular substrates ( $x, \ldots$ : sand; $\Delta$, -:vermiculite); B: paper in gerbox $(+, \ldots:$ in paper; o, —: on paper); C: paper roll). 


\section{CONCLUSÕES}

As sementes de pau-brasil germinam na temperatura de 15 a $40{ }^{\circ} \mathrm{C}$ e são indiferentes à presença de luz, com melhores resultados a $25^{\circ} \mathrm{C}$. O rolo de papel é substrato indicado para a condução de testes de germinação em laboratório e deve ser umedecido na proporção, papel : água em massa, de 1:2,5 a 1:3,0.

\section{AGRADECIMENTOS}

À Fundação de Amparo à Pesquisa do Estado de São Paulo (FAPESP), pelo apoio financeiro (Processo 2000/06422-4); ao Conselho Nacional de Desenvolvimento Científico e Tecnológico (CNPq), pelas bolsas de iniciação científica concedida a J.I.O. Mello e de produtividade concedida a C.J. Barbedo; e a Kate Massuda, Denise A. C. Bilia e Rita de Cássia L. Figueiredo-Ribeiro, pela colaboração nas atividades de laboratório e pelas sugestões.

\section{REFERÊNCIAS}

AGUIAR, F. F. A. et al. Germinação de sementes e formação de mudas de Caesalpinia echinata Lam. (pau-brasil): efeito do sombreamento. Revista Árvore, v.29, n.6, p.871-875, 2005.

ANGYALOSSY, V.; AMANO, E.; ALVES, E. S. Madeiras utilizadas na fabricação de arcos de instrumentos de corda: aspectos anatômicos. Acta Botanica Brasilica, v.19, n.4, p.819-834, 2005.

BARBEDO, C. J. Armazenamento e germinação de sementes de Caesalpinia echinata Lam. (pau-brasil). In: NOGUEIRA, R. M. C. et al. (Eds.) Estresses ambientais: danos e benefícios em plantas. Recife: Universidade Federal Rural de Pernambuco, Imprensa Universitária, 2005. p.249-255.

BORGES, E. E. L.; RENA, A. B. Germinação de sementes. In: AGUIAR, I. B.; PIÑA-RODRIGUES, F. C. M.; FIGLIOLIA, M. B. (Coords.) Sementes florestais tropicais. Brasília: ABRATES, 1993. p.83-135.

BORGES, E. E. L. et al. Caracterização de alfagalactosidase e sua relação com a germinação das sementes de Caesalpinia peltophoroides (Leguminosae - Caesalpinioideae). Revista Árvore, v. 29, n. 4, p.525-533, 2005a.

R. Árvore, Viçosa-MG, v.31, n.4, p.645-655, 2007
BORGES, I. F.et al. Maturation of seeds of Caesalpinia echinata Lam. (Brazilwood), an endangered Leguminous Tree from the brazilian Atlantic Forest. Brazilian Archives of Biology and Technology, v. 48, n. 6, p.851-861, 2005b.

BORGHETTI, F. Temperaturas extremas e a germinação das sementes. In: NOGUEIRA, R. M. C.et al. (Eds.) Estresses ambientais: danos e benefícios em plantas. Recife: Universidade Federal Rural de Pernambuco, Imprensa Universitária, 2005. p. 207-218.

BORGHETTI, F.; FERREIRA, A. G. Interpretação de resultados de germinação. In: FERREIRA, A. G.; BORGHETTI, F. (Orgs.) Germinação: do básico ao aplicado. Porto Alegre: Artmed, 2004. p.209-222.

BRASIL. Ministério da Agricultura e Reforma Agrária. Regras para análise de sementes. Brasília: SNAD/DNDU/CLAV, 1992. 365p.

FIGLIOLIA, M. B.; OLIVEIRA, E. C.; PIÑARODRIGUES, F. C. M. Análise de sementes. In: AGUIAR, I. B.; PIÑA-RODRIGUES, F. C. M.; FIGLiOLiA, M. B. (Coords.) Sementes florestais tropicais. Brasília: ABRATES, 1993. p.137-174.

GEßLER, A. et al. Ecophysiology of selected tree species in different plant communities at the periphery of the Atlantic Forest of SE-Brazil. III. Three legume trees in a semi-deciduous dry forest. Trees, v. 19, p.523-530, 2005.

GOMES, F.P. Curso de estatística experimental. 10 ed. Piracicaba: Nobel, 1982. 468p.

GOMES, S.M.S.; BRUNO, L. A influência da temperatura e substrato na germinação de sementes de urucum (Bixa orellana L.). Revista Brasileira de Sementes, v.14, n.1, p.47-50, 1992.

HENDRICKS, S. B.; TAYLORSON, R. B. Variation in the germination and animo acid leakage of seeds with temperature related to membrane phase change. Plant Physiology, v.58, n.1, p.7-11, 1976. 
LABOURiau, L. G. A germinação das sementes. Washington: OEA, 1983. 174p.

MAGUIRE, J. D. Speed of germination-aid in selection and evalution for seedling emergence vigor. Crop Science, v.2, n.2, p.176-177, 1962.

MARCOS FILHO, J. Fisiologia de sementes de plantas cultivadas. Piracicaba: FEALQ, 2005. 495p.

MWALE, S. S. et al. Effect of temperature on the germination of sunflowerr (Helianthus annnuus L.). Seed Science and Technology, v.22, p.565-571, 1994.

PONTES, C.A. et al. Influência da temperatura de armazenamento na qualidade de sementes de Caesalpinia peltophoroides Benth. (sibipiruna). Revista Árvore, v.30, n.1, p.43-48, 2006.
POPINIGIS, F. Fisiologia da semente. Brasília: AGIPLAN, 1985. 285p.

RILEY, G. J. P. Effects of high temperature on protein synthesis during germination of maize (Zea mays L.). Planta, v.151, n.1, p.75-80, 1981.

ROCHA, Y. T. Ibirapitanga: história, distribuição geográfica e conservação do paubrasil (Caesalpinia echinata Lam., Leguminosae) do descobrimento à atualidade. 2004. 457f. Tese (Doutorado em Geografia) - Universidade de São Paulo, São Paulo, 2004.

TAKAKI, M. A luz como fator de estresse na germinação de sementes. In: NOGUEIRA, R. M. C. et al. (Eds.) Estresses ambientais: danos e benefícios em plantas. Recife: Universidade Federal Rural de Pernambuco, Imprensa Universitária, 2005. p.243-248. 
